\title{
Oocyte recovery, maturation and fertilization in vitro in the puma (Felis concolor)*
}

\author{
A. M. Miller†, M. E. Roelke $\ddagger$, K. L. Goodrowe $\S$, J. G. Howard $\dagger$ and \\ D. E. Wildt $\dagger$ \\ $\uparrow$ National Zoological Park, Smithsonian Institution, Washington DC 20008, USA; $\ddagger$ Florida Game \\ and Fresh Water Fish Commission, Gainesville, FL 32601, USA; and \$Metro Toronto Zoo, \\ Box 280, West Hill, Ontario MIE 4R5, Canada
}

\begin{abstract}
Summary. Eight female pumas were treated i.m. with $1000(\mathrm{~N}=5)$ or $2000(\mathrm{~N}=3)$ i.u. PMSG followed $84 \mathrm{~h}$ later by $800 \mathrm{i}$.u. hCG. Eggs were recovered $24-26 \mathrm{~h}$ after hCG from ovarian follicles by using laparoscopy and transabdominal aspiration. Mature eggs were inseminated in vitro 4-6 h later whereas immature eggs were cultured for $24 \mathrm{~h}$ and then inseminated. Electroejaculates from 3 pumas were diluted with mKRB before insemination to evaluate the influence of sperm concentration on fertilization. Seven of 8 pumas responded with follicle development, and 140 eggs were recovered from 145 follicles $(96.6 \%$; 77 mature, 43 immature, 20 degenerate eggs; mean \pm s.e.m., $20 \cdot 0 \pm 5.9 \mathrm{eggs} /$ female). Overall fertilization rate was $43.5 \%$ (total eggs fertilized $=40$ ) despite using inseminates containing $82-99 \%$ pleiomorphic spermatozoa. Of the 36 immature oocytes matured in vitro and inseminated, 12 were fertilized even though $50 \%$ of the inseminating spermatozoa contained an acrosomal defect. Fertilization rate of mature oocytes collected from follicles appeared unrelated $(P>0.05)$ to PMSG dose or number of spermatozoa/inseminate. This study demonstrates that a high proportion of follicular eggs can be recovered laparoscopically from adult pumas treated with PMSG and hCG. These gametes are capable of being fertilized in vitro (immediately or after maturation in vitro) even with low quality semen with a high incidence of sperm pleiomorphisms.
\end{abstract}

Keywords: in vitro fertilization; puma; oocyte maturation; teratospermia

\section{Introduction}

The puma (Felis concolor) has been taxonomically subdivided into 30 subspecies and is geographically distributed in the western hemisphere from British Columbia, Alberta and Manitoba in the north to Chile and Argentina in the south (Young \& Goldman, 1946). Although existing in considerabie numbers in the western United States (Guggisberg, 1975; Anderson, 1983), there are few free-living pumas east of the Mississippi River. One extremely rare subspecies $(F$. c. coryi) exists precariously in the Big Cypress Swamp and Everglades regions of southern Florida (Belden, 1986). Fewer than 50 of these pumas, called Florida panthers, free-range in what is one of North America's most rapidly growing human population areas. Florida panther electroejaculates contain a high proportion of pleiomorphic spermatozoa (overall mean, $\sim 94 \% ; 8$ ejaculates from 5 males; J. G. Howard, M. E. Roelke \& D. E. Wildt, unpublished data), a general finding made previously for the cheetah (Acinonyx jubatus: Wildt et al., 1983, 1987b), clouded leopard (Neofelis nebulosa: Wildt et al., 1986a), 2 subspecies of leopard (Panthera pardus: Wildt et al., 1988; Brown

${ }^{*}$ Reprint requests to: Dr D. E. Wildt. 
et al., 1989), certain geographically-isolated lions (Panthera leo: Wildt et al., 1987a) and pumas from the western regions of North America ( $F$. concolor: Wildt et al., 1988). However, Florida panthers appear unique in the unusually high number of spermatozoa afflicted with deranged acrosomes (mean, $\sim 50 \%$ ), a much greater rate than observed in western pumas (mean, $1.4 \%$, Wildt et al., 1988).

The rarity of the Florida panther restricts conventional, 'controlled' reproductive biology studies. Current efforts focus on opportunistic access to animals and parallel studies of the western puma as a model subspecies. Some baseline information is available on the reproductive physiology of the western puma in captivity. Analysis of circulating oestradiol and progesterone patterns suggests that the oestrous cycle is $17-25$ days in length and that ovulation does not occur spontaneously (Bonney et al., 1981). Western pumas respond to exogenous follicle-stimulating hormone (FSH-P: Phillips et al., 1982) or pregnant mares' serum gonadotrophin (PMSG: Bonney et al., 1981; Moore et al., 1981) by developing ovarian follicles. The first successful artificial insemination of a non-domestic felid was achieved in the puma (Moore et al., 1981). Three adult females were treated with 1250 i.u. PMSG (i.m.) followed $72 \mathrm{~h}$ later by 1000 i.u. hCG (i.m.). Laparoscopy revealed that 2-6 follicles ruptured/female at 30-40 h after hCG. Each puma was inseminated in utero at laparotomy using $20-40 \times 10^{6}$ motile, electroejaculated spermatozoa/ml; one pregnancy and the birth of a cub resulted.

The present study examined the feasibility of in-vitro fertilization in a mixed population of western pumas and Florida panthers. This approach may have artificial breeding potential for the Florida panther because domestic cat eggs, recovered by laparoscopic aspiration, are capable of being fertilized in vitro and result in live-born offspring after embryo transfer (Goodrowe et al., $1988 \mathrm{~b}$ ). Because pumas exhibit an extreme case of teratospermia, this study also permitted evaluation of the impact of structurally abnormal spermatozoa on sperm/egg interaction. Spermatozoa from teratospermic domestic cats appear to be compromised in ability to penetrate homologous oocytes in vitro (Howard et al., 1988, 1989). Our specific objectives were to (1) determine the effects of PMSG and hCG on ovarian follicle development and oocyte maturation in pumas maintained chronically in captivity or recently captured from the wild; and (2) evaluate the ability of laparoscopicallyrecovered follicular oocytes to become fertilized in vitro with electroejaculates containing high proportions of pleiomorphic spermatozoa.

\section{Materials and Methods}

Animals. The study was conducted in Gainesville, Florida (USA) in June 1988 using 8 adult female pumas, 6 of the Texas subspecies ( $F$. c. stanleyana), one Florida panther $(F . c$. coryi) and one hybrid female of unknown origin (Table 1). Three of the western females (Nos 3,5 and 7) were wild caught in southwest Texas 3-6 weeks before study onset; therefore, reproductive histories were unknown. The 3 remaining western pumas (Nos $1,4,6)$ and one hybrid female (No. 2) had been maintained in captivity in northern Florida for more than 2 years or since birth, respectively. All were presumed nulliparous except Puma 6 which was a known proven breeder. The Florida panther (No. 8) had been in captivity since April 1987 and had not reproduced or been observed in behavioural oestrus. Three adult males served as sperm donors: (1) a wild-caught puma (No. 1) from Texas with an unknown reproductive history and captured 4 weeks before study onset; (2) a captive born hybrid male and proven breeder (No. 2); and (3) a Florida panther (No. 3) maintained in captivity since 1984 with no history of reproducing. On 3 occasions from 1985 to 1987 , Male 3 was electroejaculated under anaesthesia and produced the following average semen characteristics: semen volume, $1.3 \mathrm{ml}$; sperm concentration, $13 \times 10^{6} / \mathrm{ml}$ ejaculate; sperm motility rating, $85 \%$; proportion of pleiomorphic spermatozoa, $96 \cdot 3 \%$; proportion of spermatozoa with abnormal acrosomes, $48 \cdot 3 \%$.

Captive pumas in Florida were maintained individually or in pairs (females) in outdoor enclosures and provided with continuous access to water and either Nebraska Brand Feline, Canine Racing Diet (Lincoln, NE, USA) or Western Plateau Feline Diet (Amarillo, TX, USA) (1.4-2.4 kg/animal/day). Before transport from Texas to Florida, the newly captured pumas were maintained in individual outdoor enclosures and fed red meat (2.3-3.6 kg/day). These animals were placed in crates $12 \mathrm{~h}$ before scheduled gonadotrophin treatment and shipped by air transport (over a 6-h interval) to Gainesville.

Induction of ovarian activity, laparoscopy and oocyte recovery. Female pumas received i.m. injections of $1000 \mathrm{i} . \mathrm{u}$. $(\mathrm{N}=5)$ or 2000 i.u. $(\mathrm{N}=3$ ) PMSG (Equitech Inc., Atlanta, GA, USA). To ensure complete hormone delivery, 
females were sedated with 40 mg diazepam i.m. (Valium ${ }^{\circledR}$ : Elkins-Sinn Inc., Cherryhill, NJ, USA) and $200-400$ mg ketamine hydrochloride (HCl) i.m. (Vetalar ${ }^{\circledR}$ : Parke-Davis, Morris Plains, NJ, USA) before the PMSG dose. Precisely $84 \mathrm{~h}$ after PMSG, each puma was injected with 800 i.u. hCG i.m. (Sigma Chemical Co., St Louis, MO, USA) but without pre-treatment sedation. For the western pumas being transported from Texas to Florida, PMSG was administered immediately after translocation. The 84-h period between PMSG and hCG was based on findings suggesting that this interval maximized intrafollicular egg maturation in the domestic cat (Miller et al., 1988).

All oocyte recovery attempts were made 24-26 h after hCG. A surgical plane of anaesthesia was induced with ketamine $\mathrm{HCl}$ i.m. ( $10 \mathrm{mg} / \mathrm{kg}$ body weight), and each female was intubated and maintained on inhalation anaesthesia of halothane and oxygen. Standard laparoscopy procedures were used (Wildt et al., 1981; Phillips et al., 1982). A pneumoperitoneum was established using room air, and the ovaries were observed using a 10 -mm diameter, $180^{\circ}$ laparoscope assembly placed mid-ventrally through a $20-\mathrm{mm}$ skin incision. A Verres needle probe ( $2 \mathrm{~mm}$ in diameter) was used to manipulate the reproductive organs into view and aid counting ovarian follicles or corpora haemorrhagica or estimating follicle size. Laparoscopic oocyte aspirations were performed using the procedures described by Goodrowe et al. (1988b) for the domestic cat. For aspirations, a 4-cm long, 22-gauge needle attached to size 100 polyethylene tubing (i.d. $0.86 \mathrm{~mm}$; Clay Adams, Parsippany, NJ, USA) was rinsed with 2-3 ml of a modified Krebs'Ringer bicarbonate solution (mKRB; Toyoda \& Chang, 1974; Niwa et al., 1985; NIH Media Unit, Bethesda, MD, USA) containing $4 \mathrm{mg}$ bovine serum albumin/ml (Fraction V, Miles Laboratories Inc., Elkhart, IN, USA) and 40 units heparin $/ \mathrm{ml}$ medium. A siliconized $7 \mathrm{ml}$ collection tube (Terumo Medical Corp., Elkton, MD, USA) was attached to the free end of the polyethylene tubing, and the aspiration system was driven by a vacuum pump (Gast Manufacturing Corp., Benton Harbor, MI, USA). The Verres probe was used to stabilize the reproductive tract, and the aspiration needle was inserted through the abdominal wall ventro-medial to each ovary. Distinct follicles $\geq 2 \mathrm{~mm}$ in diameter were perforated with the needle while applying negative pressure $(100 \mathrm{mmHg})$ with the vacuum pump. After aspirating follicles from one ovary, the collection tube and aspiration needle were replaced and the procedure repeated for the contralateral ovary. Collection tubes from each animal were emptied into separate plastic culture dishes which were examined by stereomicroscopy. All eggs were transferred immediately into fresh mKRB medium (without heparin) and placed in a $5 \% \mathrm{CO}_{2}$ in air, humidified environment at $38^{\circ} \mathrm{C}$. Each cumulus cell-oocyte complex was evaluated for maturational status and classified as: (1) mature, corona radiata and cumulus oophorus cells loosened and expanded; (2) immature, tightly compacted corona radiata; or (3) degenerate, egg appeared abnormal, pale and/or lacked a corona radiata. Eggs were washed 3 times in mKRB under lightweight paraffin oil (Fisher Scientific Co., Fair Lawn, NJ, USA), placed in fresh medium and returned to the incubator.

Semen collection and processing. Spermatozoa were obtained by electroejaculation using a previously described, standardized procedure (Wildt et al., 1983, 1987b, 1988; Howard et al., 1986). In brief, this involved inducing a surgical plane of anaesthesia with ketamine $\mathrm{HCl}\left(10 \mathrm{mg} / \mathrm{kg}\right.$ body weight; i.m.) or Telazol ${ }^{\circledR}(8 \mathrm{mg} / \mathrm{kg}, \mathrm{A}$. H. Robbins, Richmond, VA, USA). Each animal was given 80 electrical stimuli of similar voltage (2-8 V) and milliamperage (20 175 mA) administered over $\sim 26 \mathrm{~min}$. An AC, $60-\mathrm{Hz}$ sine-wave electroejaculator (P-T Electronics, Boring, OR, USA) and rectal probe were used to deliver stimuli in 3 series of 30,30 and 20 stimuli, respectively, with a 3-5 min rest period permitted between series.

Electroejaculate volume was recorded, and a $10 \mu \mathrm{l}$ sample was used to calculate sperm concentration using procedures described previously (Wildt et al, 1983, 1988; Howard et al., 1986). An undiluted 5- $\mu$ l sample of ejaculate was examined $(\times 250)$ immediately after collection by 2 technicians to provide subjective estimates of sperm percentage motility and progressive status $(0$ to 5 scale; $0=$ no forward progression or movement to $5=$ rapid, linear forward progression; Wildt et al., 1983, 1988; Howard et al., 1986). An average motility rating was calculated for each male. Gross morphological assessments were made by fixing a $25 \mu \mathrm{l}$ sample of the semen in $1 \%$ glutaraldehyde and later evaluating 200 spermatozoa/ejaculate by phase-contrast microscopy $(\times 1000)$.

In earlier studies of domestic cat fertilization in vitro (Goodrowe et al., 1988b), electroejaculates were subjected to swim-up' processing (low-speed centrifugation and supernatant removal followed by sperm migration from the pellet into fresh culture medium). This permitted recovery of mostly motile, structurally normal spermatozoa. Preliminary studies indicated that swim-up processing was ineffective in the puma, probably because of fewer spermatozoa/ml of ejaculate, poorer sperm motility ratings and more abnormal sperm forms than observed in the domestic cat. Because puma electroejaculates were low in volume and overall quality, sufficient sperm numbers were available to permit only one semen processing treatment/male: (1) diluted in $\mathrm{mKRB}$, insemination concentration was $2.0 \times 10^{6}$ motile spermatozoa $/ \mathrm{ml}$ (Male 1); (2) semen centrifugation $(300 \mathrm{~g}, 8 \mathrm{~min})$, supernatant discarded and pellet diluted in mKRB to $1.0 \times 10^{6}$ motile spermatozoa/ml (Male 2$)$; and (3) semen centrifugation $(300 \mathrm{~g}, 8 \mathrm{~min})$, supernatant discarded and pellet diluted in mKRB to $0.2 \times 10^{6}$ motile spermatozoa $/ \mathrm{ml}$ (Male 3 ). During the processing to pre-insemination interval, spermatozoa were maintained at room temperature in mKRB, and eggs from at least 3 donors were inseminated with spermatozoa from each male.

Insemination and egg/sperm co-culture. Mature eggs were inseminated with a $100 \mu$ l sample of the diluted sperm suspension from Males 1 and 2. Therefore, these eggs were placed with $0.2 \times 10^{6}$ and $0.1 \times 10^{6}$ total spermatozoa, respectively, under oil in a $35 \times 10 \mathrm{~mm}$ Petri dish. Eggs from individual females were maintained in separate sperm cell drops ( $\leqslant 10$ oocytes/drop) and the fertilization dishes were placed into a humidified, $5 \% \mathrm{CO}_{2}$ in air incubator at $38^{\circ} \mathrm{C}$. The same incubator system was used to culture immature eggs in mKRB for $24 \mathrm{~h}$ to advance maturation. Eggs with an expanded corona radiata and cumulus cell complex were considered to have matured in vitro, were inseminated with $100 \mu \mathrm{l}$ of the sperm suspension from Male $3\left(0.02 \times 10^{6}\right.$ spermatozoa) and cultured under the same conditions as described for mature oocytes. Degenerate eggs were excluded from culture. To determine the rate of 
parthenogenesis, control eggs (representative oocytes from each PMSG treatment and maturational status were used; total $n=12$ ) were cultured under standard conditions in medium containing no spermatozoa. At $18-20 \mathrm{~h}$ after insemination, eggs were removed from the incubator and washed 3 times in a $0 \cdot 2 \%$ hyaluronidase solution (Type $1-S$, from bovine testes; Sigma Chemical Co.) for $3 \mathrm{~min}$ to remove residual cumulus cells and loosely attached spermatozoa. Eggs were returned to the incubator in $100 \mu \mathrm{l}$ drops of fresh, equilibrated mKRB under oil and examined $24 \mathrm{~h}$ after insemination.

Assessment of fertilization. Fertilization criteria were those described previously (Goodrowe et al., 1988b) and were dependent on the presence of 2 polar bodies, 2 pronuclei or cleavage to at least the 2-cell stage. Eggs with more than 2 nuclear structures within the cytoplasm were considered polyspermic. Puma eggs, like oocytes from other felid species (Goodrowe et al., 1988b, 1989), were extremely dark and opaque making it impossible to identify accurately the germinal vesicle or pronuclei using conventional light microscopy. Therefore, uncleaved eggs were treated with a DNA-specific fluorescent stain, Hoechst 33342 (H342; bisbenzamine; Sigma Chemical Co.), as described for a variety of mammals (Pursel et al., 1985) including the domestic cat (Goodrowe et al., 1988b). Eggs were counterstained with $0 \cdot 1 \%$ Trypan blue (Sigma Chemical Co.) for $1-2 \mathrm{~min}$, incubated in $\mathrm{H} 342\left(0.09 \mathrm{mg} / \mathrm{ml}, 15 \mathrm{~min}, 23^{\circ} \mathrm{C}\right)$ and examined using differential interference contrast (DIC) and fluorescence optics $(\times 250$ and $\times 400)$ for germinal vesicles, pronuclei, polar bodies or polyspermic fertilization.

Statistics. Average values are reported as means \pm the standard error of the mean (s.e.m.). A Student's $t$ test was used to evaluate differences in the mean numbers of mature or immature eggs collected between PMSG dosages. The proportion of mature, immature, degenerate or fertilized eggs was compared between PMSG treatments by $\chi^{2}$ analysis. Potential differences among males in the numbers of morphologically abnormal spermatozoa produced, fertilization rate in vitro and incidence of polyspermia also were evaluated by $\chi^{2}$ statistics.

\section{Results}

The combined use of PMSG and hCG was effective in stimulating ovarian activity in 7 of 8 pumas (Table 1). Only Female 8 (the Florida panther) had no follicular or luteal activity at the laparoscopy after hCG; this animal died abruptly 2 months later from kidney disease and a hyperthyroidism condition. In the pumas responding to gonadotrophin stimulation, follicle ( $\geq 2 \mathrm{~mm}$ in diameter) numbers ranged from 8 to 52 /female (Table 1). One animal (No. 1) apparently began ovulating before laparoscopic aspiration, as fresh corpora haemorrhagica were observed on both ovaries. The 3 wild-caught pumas tended to produce more follicles $(30.6 \pm 10 \cdot 7)$ than the females chronically maintained in captivity $(13.3 \pm 2 \cdot 6)$ but the difference was not significant $(P=0 \cdot 12)$. A total of 140 eggs from 145 follicles $(96.6 \%$ recovery) was collected from the 7 pumas (mean, $20.0 \pm 5.9$ eggs/female). Of these, 77 were classified as mature $(55 \cdot 0 \%), 43$ as immature $(30 \cdot 7 \%)$ and 20 $(14 \cdot 3 \%)$ were characterized as degenerate. The immature eggs were collected from 4 pumas and $93 \%$ of these were recovered from the recently captured animals.

A total of 108 eggs (71 matured in vivo; 37 matured in vitro) was inseminated, and 16 of these were damaged, lost or could not be precisely classified after staining. Overall fertilization rate for all oocytes inseminated was $43.5 \%$ (total eggs fertilized $=40$ ), averaging $50.0 \%$ for those matured in vivo and $33.3 \%$ for those matured in vitro (Table 1). A total of 10 eggs had cleaved to the 2-cell stage of development within $24 \mathrm{~h}$ of insemination. Parthenogenetic cleavage was not observed in any control egg.

Although limited numbers of animals were tested, the data were examined on the basis of PMSG dose. Pumas treated with 1000 i.u. PMSG and demonstrating ovarian activity $(\mathrm{N}=4)$ tended to produce more ovarian follicles (mean, $24.8 \pm 9 \cdot 5$ ) than those given 2000 i.u. (mean, $15 \cdot 3 \pm 2 \cdot 9)$ but the difference was not significant $(P=0 \cdot 14)$. Neither mean number of immature eggs recovered ( 1000 i.u., $6 \cdot 5 \pm 3.3$ versus 2000 i.u., $5 \cdot 7 \pm 5 \cdot 7$ ), mean number of mature eggs recovered/female (1000 i.u., $14 \cdot 3 \pm 4 \cdot 1$ versus 2000 i.u., $6.7 \pm 2 \cdot 1$ ) or overall fertilization rate in vitro was influenced by PMSG treatment $(P>0.05)$. Of the 39 mature eggs inseminated in the 1000 i.u. group, 6 cleaved and an additional 13 fertilized as determined by Hoechst staining (overall rate, $48 \cdot 7 \%$ ). Of the 17 mature eggs recovered from the 2000 i.u. PMSG group and co-cultured with spermatozoa, 4 cleaved and 5 exhibited intracellular evidence of fertilization (overall rate, $52.9 \%$ ).

Semen characteristics for the 3 sperm donors are depicted in Table 2 . Overall, $50 \%$ or fewer of all spermatozoa demonstrated forward progressive motility, and $82 \%$ or more of all cells exhibited 


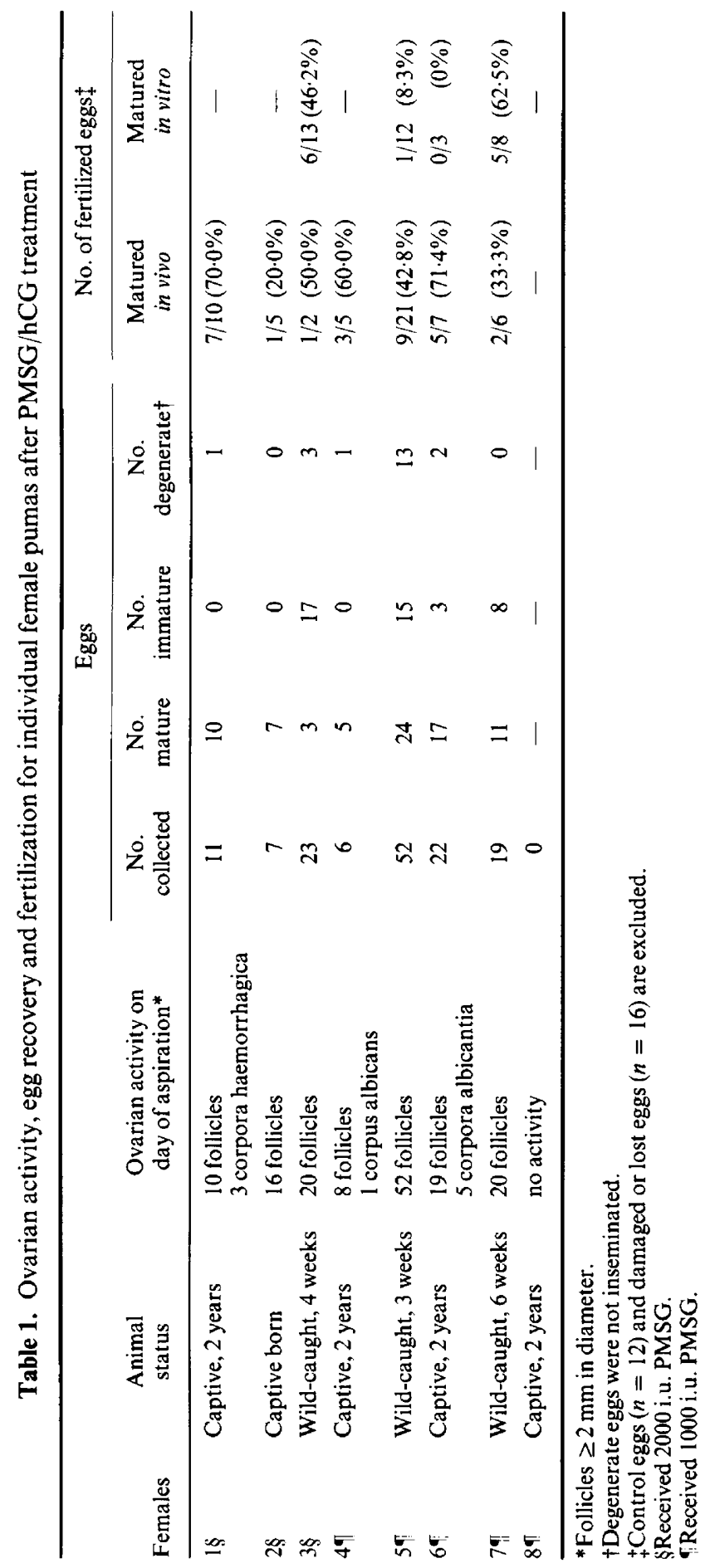


Table 2. Ejaculate characteristics and in-vitro fertilization results for individual male pumas

\begin{tabular}{|c|c|c|c|}
\hline & $\begin{array}{c}\text { Male I } \\
\left(2 \cdot 0 \times 10^{6}\right)^{*}\end{array}$ & $\begin{array}{c}\text { Male 2 } \\
\left(1.0 \times 10^{6}\right)^{*}\end{array}$ & $\begin{array}{c}\text { Male } 3 \dagger \\
\left(0.2 \times 10^{6}\right)^{*}\end{array}$ \\
\hline Ejaculate volume (ml) & $0 \cdot 37$ & $1 \cdot 52$ & 1.42 \\
\hline Spermatozoa $/ \mathrm{ml}$ ejaculate $\left(\times 10^{-6}\right)$ & $27 \cdot 0$ & $1 \cdot 3$ & $4 \cdot 0$ \\
\hline Sperm motility $(\%)$ & 40 & 50 & 40 \\
\hline Sperm progressive status & $2 \cdot 5$ & $2 \cdot 5$ & $3 \cdot 0$ \\
\hline $\begin{array}{l}\text { Morphologically abnormal } \\
\text { spermatozoa (\%) } \\
\text { Abnormal head shape } \\
\text { Abnormal acrosome } \\
\text { Abnormal/missing midpiece } \\
\text { Bent midpiece with droplet } \\
\text { Bent midpiece without droplet } \\
\text { Proximal/distal droplet } \\
\text { Tightly coiled flagellum } \\
\text { Bent flagellum }\end{array}$ & $\begin{array}{r}98 \\
0 \\
5 \\
1 \\
16 \\
5 \\
4 \\
66 \\
1\end{array}$ & $\begin{array}{r}82 \\
0 \\
6 \\
6 \\
6 \\
14 \\
20 \\
20 \\
10\end{array}$ & $\begin{array}{r}99 \\
12 \\
50 \\
3 \\
1 \\
1 \\
14 \\
18 \\
0\end{array}$ \\
\hline $\begin{array}{l}\text { No. of fertilized eggs/ } \\
\text { total eggs }(\%)\end{array}$ & $\begin{array}{r}11 / 21 \\
(52 \cdot 4)\end{array}$ & $\begin{array}{r}16 / 33 \\
(48 \cdot 5)\end{array}$ & $\begin{array}{l}13 / 38_{\ddagger}^{+} \\
(34 \cdot 2)\end{array}$ \\
\hline $\begin{array}{l}\text { No. of polyspermic eggs/ } \\
\text { total eggs }(\%)\end{array}$ & $\begin{array}{l}2 / 21 \\
(9 \cdot 5)\end{array}$ & $\begin{array}{l}3 / 33 \\
(9 \cdot 1)\end{array}$ & $\begin{array}{l}3 / 38 \\
(7.9)\end{array}$ \\
\hline
\end{tabular}

*Motile spermatozoa $/ \mathrm{ml}$; insemination concentration $/ \mathrm{ml}$.

†Felis concolor coryi (Florida panther) male.

‡Eggs were matured in vitro $24 \mathrm{~h}$ before insemination.

structural deformities. In Males 1 and 2, the majority of morphological defects consisted of midpiece and flagellar abnormalities ( 93 and $76 \%$, respectively) whereas $62 \%$ of the spermatozoa from Male 3 (the Florida panther) had head deformities, including 50\% with deranged acrosomes. Although processing procedures and total number of spermatozoa inseminated varied among males, the overall fertilization rate of oocytes did not differ, being $52.4 \%$ for Male $1,48.5 \%$ for Male 2 and $34.2 \%$ for Male $3(P>0.05)$. However, spermatozoa from Male 3 were used to inseminate in-vitro-matured eggs. Even under these conditions, more than one-third of the eggs exposed to the low quality spermatozoa of Male 3 demonstrated evidence of fertilization. The overall incidence of polyspermy was $8.8 \%$ and, among males, appeared unrelated to individual or numbers of spermatozoa inseminated (Table 2).

\section{Discussion}

As observed in the domestic cat (Goodrowe et al., 1988b), a single injection of PMSG followed by hCG stimulated sufficient ovarian activity in the puma to permit collection of high quality, intrafollicular oocytes capable of being fertilized in vitro. The PMSG to hCG interval, laparoscopic aspiration technique and egg/sperm co-culture system developed for the domestic cat were effective for the puma, confirming previous assertions that the cat is a suitable model for developing embryo strategies for non-domestic felid species (Wildt et al., 1986b). The data, however, re-emphasized the variability to be expected in ovarian response and egg/embryo quality following hormonal treatment, both among and within species. Striking differences in intrafollicular egg integrity and in-vitro fertilizability exist between the domestic cat and leopard cat ( $F$. bengalensis), a small, non-domestic felid indigenous to southeast Asia (Goodrowe et al., 1989). Although capable of interbreeding with domestic cats and producing hybrid offspring, leopard cats given the same $\mathrm{PMSG} / \mathrm{hCG}$ regimen and subjected to the same laparoscopic recovery and culture procedures as 
the domestic cat produce inferior quality eggs and overall lower fertilization rates in vitro. Furthermore, a higher proportion of leopard cat eggs were classified as degenerate $(\sim 45 \%)$ compared to domestic cat eggs ( 14\%; Goodrowe et al., 1988b) and the puma eggs (14.3\%) studied here. Although the basic mechanisms associated with follicular development, egg maturation and fertilizability probably are similar among felid species, subtle and perhaps critical species-specific differences may exist. This variation illustrates the evolutionary diversity of the felids and indicates that there are physiological differences among species which may present formidable challenges to the practical application of artificial breeding strategies.

The variation in PMSG-induced ovarian responses among domestic cats has been attributed, in part, to individual differences in animal sensitivity (Wildt et al., 1978; Cline et al., 1980). The greatest variability among pumas was in the numbers of ovarian follicles induced to develop and eggs recovered/female. Some of this variation may have been due to differences in reproductive status at the start of treatment. Pumas cycle throughout the year in North America (Anderson, 1983), and it is possible that some females were in a follicular phase which was enhanced further by the PMSG-hCG treatment. A single injection of $1000 \mathrm{i} . \mathrm{u}$. PMSG resulted in a range of 8-52 follicles which was greater than the 2-6 CL observed by Bonney et al. (1981) after treating pumas with 1250 i.u. PMSG. Although this difference may be attributable to variations in PMSG source and potency, Bonney et al. (1981) administered hCG $72 \mathrm{~h}$ after PMSG compared to $84 \mathrm{~h}$ in our study. In domestic cats, extending the PMSG to hCG interval tends to increase the number of ovarian follicles produced and the total number of eggs recovered (Miller et al., 1988).

The finding that one puma was ovulating $26 \mathrm{~h}$ after hCG suggests that any further delay in follicle aspiration after hCG would result in ovulation and loss of eggs before laparoscopic recovery. Even so, $\sim 30 \%$ of all eggs were immature at aspiration, indicating that the asynchronous follicles were being recruited which resulted in eggs of varied maturational status. The rate of human intrafollicular egg maturation in vivo is directly related to the interval of follicle exposure to hCG (Botero-Ruiz et al., 1981). Perhaps the more immature puma follicles were slow to respond to PMSG, experienced an inadequate exposure interval to hCG and, thus, produced immature eggs. The kinetics of in-vivo or in-vitro egg maturation have not been studied extensively in carnivores. However, we recently developed an in-vitro maturation system for follicular oocytes recovered from ovariectomized domestic cats (Johnston et al., 1989). Of the immature antral oocytes cultured with gonadotrophins, $54 \%$ achieved metaphase II by $48 \mathrm{~h}$. In the present study, based on subjective evaluation of cumulus complexes and corona radiata expansion, $100 \%$ of the oocytes appeared to have matured in vitro after $24 \mathrm{~h}$ in culture. Treating the females with gonadotrophins before collection and a high selectivity of oocytes before culture probably enabled all puma eggs to mature visibly in vitro. The in-vitro fertilization rate for these eggs $(\sim 33 \%)$ was very similar to that observed for domestic cat eggs matured in vitro (36\%).

Wild-caught pumas responded well to the gonadotrophin treatment despite recent capture and long-distance transport. Even though receiving the PMSG treatment immediately after transit, these females produced high numbers of quality eggs which fertilized at a rate no different from that of pumas maintained in captivity for more than 2 years. Adrenal activity in captive pumas is very sensitive to an acute stress (Wildt et al., 1988): males are capable of secreting massive concentrations of glucocorticoids as demonstrated by a 6-fold increase in circulating cortisol values within $1.5 \mathrm{~h}$ of combined anaesthesia and electroejaculation (Wildt et al., 1988). Unlike in certain felid species (Brown et al., 1988, 1989; Wildt et al., 1988), elevated cortisol has no effect on testosterone production in pumas (Wildt et al., 1988). A wild species like the puma is exposed continuously to stressors, and survival is highly dependent on adaptive abilities to minimize any adverse effects of hyperadrenal activity on reproduction. No doubt, the transported pumas in our study were experiencing stress, yet the females readily responded to exogenous gonadotrophins. Our collective observations of the puma suggest that gonadal functions in both the male (testosterone production) and female (PMSG-induced follicle development) appear relatively resilient to factors which potentially elicit stress. 
Sperm capacitation is a prerequisite to fertilization, and capacitating spermatozoa of many species requires extensive processing in vitro (Brackett, 1981; Yanagimachi, 1981). We have demonstrated that domestic cat spermatozoa readily capacitate after low-speed centrifugation and 1-h 'swim-up' processing (Goodrowe et al., 1988a). Puma spermatozoa also were easily capacitated, and eggs were fertilized by ejaculates which either were centrifuged only and the seminal plasma removed or simply used undiluted and unprocessed. This was fortunate because preliminary studies indicated that the overall poor ejaculate quality of pumas precluded using swim-up processing for recovering spermatozoa. Howard et al. (1989) reported that removing the seminal plasma from domestic cat ejaculates is not necessary for cat spermatozoa to bind and penetrate homologous eggs. Apparently the decapacitation factor which plays such an important role in controlling fertilization in some species (Fraser, 1984; Thomas et al., 1986; Shivaji \& Bhagava, 1987) either does not exist or has little consequence in either the domestic cat or puma.

All male pumas produced high numbers of pleiomorphic spermatozoa/ejaculate, a finding which was not surprising in view of similar observations in a variety of other felids of large size (Wildt et al., 1983, 1987a, 1988). The aetiology of this characteristic is unknown, although several studies have related the number of abnormal spermatozoa in felid ejaculates to a lack of genetic variability (O'Brien et al., 1986; Wildt et al., 1983, 1987a, b). Florida panthers produce fewer polymorphic loci than do any other puma subspecies studied to-date (Roelke, 1988; M. E. Roelke \& S. J. O'Brien, unpublished data). Additionally, 8 of 17 (47\%) free-ranging males examined during field capture episodes are unilaterally cryptorchid (M. E. Roelke, unpublished observations), a condition which is highly heritable in other species (Farrer et al., 1985; Knap, 1986; MacKellar, 1987). These findings suggest that the Florida panther has a narrow genetic base and that inbreeding may be contributing to certain reproductive characteristics including the high incidence of abnormal acrosomes.

It is important to define more clearly the impact of teratospermia on the ability of a spermatozoon to participate in fertilization and normal embryo development. A high incidence of teratospermia reduces fertility in non-felid species (Hulet et al., 1965; Singleton \& Shelby, 1972; Munro, 1981; Saacke et al., 1988; Bader et al., 1988) and decreases in-vitro fertilization rates in humans (Bostofte et al., 1982; Jeulin et al., 1986). Spermatozoa from teratospermic, domestic cat ejaculates are less capable of binding and penetrating zona pellucida-free hamster eggs and zona-intact domestic cat eggs in vitro than are those from normospermic ejaculates (Howard et al., 1988, 1989). The in-vitro fertilization rate of puma eggs using western puma (50\%) and Florida panther (34\%) spermatozoa was considerably less than the $\sim 75 \%$ rate for domestic cat eggs using normospermic ejaculates and the same culture system. None the less, it was rather remarkable that 1 in 3 in-vitro matured puma eggs co-cultured with Florida panther spermatozoa demonstrated evidence of fertilization, especially considering that $50 \%$ of all spermatozoa contained a severely deformed acrosome. Although these ejaculates contain extreme numbers of structurally abnormal spermatozoa, it is apparent that fertility is not completely compromised. This would explain why certain males have sired litters in the wild, even though opportunistic semen evaluations have indicated a comparable level of teratospermia (M. E. Roelke, J. G. Howard \& D. E. Wildt, unpublished observations). The actual reproductive performance of the Florida panther and the level at which teratospermia begins to contribute to suboptimal fertility remain to be determined. Field observations indicate that not all adult Florida panthers reproduce (M. E. Roelke, unpublished observations). Male 3, in captivity for more than 4 years, has failed to breed naturally even though exposed to several oestrous females. It will be difficult to determine the impact of teratospermia on fertility of the current Florida panther population. However, it is encouraging that ejaculates which would be considered extremely poor quality by conventional assessment standards could be used to produce embryos. Although the biological competence of these embryos in vivo remains to be determined, the present results suggest that in-vitro fertilization may be a viable alternative for ensuring that such individuals contribute to a subspecies recovery plan. 
We thank Dr Donald Forrester, Dr George Kollias, Dr Elliot Jacobson, Dr Collin Burrows, Dr Martin Drost and Dr Victor Shille and the University of Florida, College of Veterinary Medicine, Gainesville, for providing generous access to equipment, laboratories and surgical facilities; Tom Logan, Bureau Chief of Research, Steve Parker and Robert Belden of the Florida Game and Fresh Water Fish Commission; and John Lucas and the staff at White Oak Plantation and the Tallahasse Museum for co-operation and assistance. Portions of this project were supported by grants from the National Institutes of Health (HD 23853) and Friends of the National Zoo (to D.E.W.), the U.S. Fish and Wildlife Service through Endangered Species Grant funding (to M.E.R.) and the Blackstock Foundation (to K.L.G.). A.M.M. is supported, in part, by the Women's Committee of the Smithsonian Associates.

\section{References}

Anderson, A.E. (1983) A critical review of literature on the puma (Felis concolor). Spec. Rep. No. 54, Colo. Div. Wdlf.

Bader, H., Hoppen, H.O., Wockener, A. \& Merkt, H. (1988) Case studies in stallions with fertility problems: endocrine and spermatological aspects. Proc. Ilth Int. Cong. Anim. Reprod. A.I., Dublin 3, 367, abstr.

Belden, R.C. (1986) Florida panther recovery plan implementation: a 1983 progress report. In Cats of the World: Biology, Conservation and Management Proceedings of the 2nd International Cat Symposium, pp. 159-172. Eds S. D. Miller \& D. D. Everitt. Kingsville.

Bonney, R.C., Moore, H.D.M. \& Jones, D.M. (1981) Plasma concentrations of oestradiol-17 $\beta$ and progesterone, and laparoscopic observations of the ovary in the puma (Felis concolor) during oestrus, pseudopregnancy and pregnancy. J. Reprod. Fert. 63, $523-531$.

Bostofte, E., Serup, J. \& Rebbe, H. (1982) Relation between morphologically abnormal spermatozoa and pregnancies obtained during a twenty-year follow-up period. Int. J. Androl. 5, 379-386.

Botero-Ruiz, W., Laufer, N., Decherney, A.H., Polan, M.L., Haseltine, F.P. \& Behrman, H.R. (1981) The relationship between follicular fluid steroid concentration and successful fertilization of human oocytes in vitro. Fert. Steril. 41, 820-826.

Brackett, B.G. (1981) Applications of in vitro fertilization. In New Technologies in Animal Breeding, pp. 141-161. Eds G. E. Seidel, Jr, S. Seidel \& B. G. Brackett. Academic Press, New York.

Brown, J.L., Goodrowe, K.L., Simmons, L.G., Armstrong, D.L. \& Wildt, D.E. (1988) Evaluation of the pituitarygonadal response to $\mathrm{GnRH}$, and adrenal status, in the leopard (Panthera pardus japonensis) and tiger (Panthera tigris). J. Reprod. Fert. 82, 227-236.

Brown, J.L., Wildt, D.E., Phillips, L.G., Seidensticker, J., Fernando, S.B.U., Miththapala, S. \& Goodrowe, K.L. (1989) Ejaculate characteristics, and adrenal pituitary-gonadal interrelationships in captive leopards (Panthera pardus kotiya) isolated on the island of Sri Lanka. J. Reprod. Fert. 85, 605-614.

Cline, E.M., Jennings, L.L. \& Sojka, N.J. (1980) Breeding laboratory cats during artificially induced estrus. Lab. Anim. Sci. 30, 1003-1005.

Farrer, J.H., Sikka, S.C., Xie, H.W., Constantinide, D. \& Rajfer, J. (1985) Impaired testosterone biosynthesis in cryptorchidism. Fert. Steril. 44, 125-132.
Fraser, L.R. (1984) Mouse sperm capacitation in vitro involves loss of a surface-associated inhibitory component. J. Reprod. Fert. 72, 373-384.

Goodrowe, K.L., Miller, A.M. \& Wildt, D.E. (1988a) Capacitation of domestic cat spermatozoa as determined by homologous zona pellucida penetration. Proc. IIth Int. Cong. Anim. Reprod. A.I., Dublin 3, 245 , abstr.

Goodrowe, K.L., Wall, R.J., O'Brien, S.J., Schmidt, P.M. \& Wildt, D.E. (1988b) Developmental competence of domestic cat follicular oocytes after fertilization in vitro. Biol. Reprod. 39, 355-372.

Goodrowe, K.L., Miller, A.M. \& Wildt, D.E. (1989) In vitro fertilization of gonadotropin-stimulated leopard cat (Felis bengalensis) follicular oocytes. J. exp. Zool. (in press).

Guggisberg, C.A.W. (1975) Wild Cats of the World, pp. 328. Taplinger Publishing Co., New York.

Howard, J.G., Bush, M. \& Wildt, D.E. (1986) Semen collection, analysis and cryopreservation in nondomestic mammals. In Current Therapy in Theriogenology, pp. 1047-1053. Ed. D. A. Morrow. W. B. Saunders Co., Philadelphia.

Howard, J.G., Barone, M.A., Clingerman, K.J., Bush, M. \& Wildt, D.E. (1988) Influence of teratospermia, culture media and a sperm swim-up technique on penetration of zona-free hamster ova by domestic cat spermatozoa. Proc. 1/th Int. Cong. Anim. Reprod. A.I., Dublin 3, 332, abstr.

Howard, J.G., Hurlbut, S.L. \& Bush, M. (1989) Compromised zona binding and penetration of homologous oocytes by spermatozoa from teratospermic domestic cats. Biol. Reprod. 40 (Suppl. 1), 161, abstr.

Hulet, C.V., Foote, W.C. \& Blackwell, R.L. (1965) Relationship of semen quality and fertility in the ram to fecundity in the ewe. J. Reprod. Fert. 9, 311-341.

Jeulin, C., Feneux, D., Serres, C., Jouannet, P., GuilletRosso, R., Belaisch-Allart, J., Fryman, R. \& Testart, J. (1986) Sperm factors related to failure in human in-vitro fertilization. J. Reprod. Fert. 76, 735-744.

Johnston, L.A., O'Brien, S.J. \& Wildt, D.E. (1989) In vitro maturation and fertilization of domestic cat follicular oocytes. Gamete Res. 24, 343-356.

Knap, P.W. (1986) Congenital defects inheritance of AI boars: genetic parameters and breeding value estimation procedures. Livestock Prod. Sci. 15, $337-352$. 
MacKellar, A. (1987) Cryptorchidism. In Andrology, pp. 53-68. Eds J. P. Pryor \& L. I. Lipshultz. Butterworths \& Co., London.

Miller, A.M., Goodrowe, K.L. \& Wildt, D.E. (1988) Influence of gonadotropin source and treatment interval on in vitro fertilization of domestic cat oocytes. Biol. Reprod. 38 (Suppl. 1), 73, abstr.

Moore, H.D.M., Bonney, R.C. \& Jones, D.M. (1981) Induction of oestrus and successful artificial insemination in the cougar, Felis concolor. Vet. Rec. 108, 282-283.

Munro, I.B. (1981) Bovine semen characteristics and fertility. J. Reprod. Fert. 2, 513-571.

Niwa, K., Ohara, K., Hosoi, Y. \& Iritani, A. (1985) Early events of in-vitro fertilization of cat eggs by epididymal spermatozoa. J. Reprod. Fert. 74, 657-660.

O'Brien, S.J., Wildt, D.E. \& Bush, M. (1986) The cheetah in genetic peril. Sci. Amer. 5, 84-92.

Phillips, L.G., Simmons, L.G., Bush, M., Howard, J.G. \& Wildt, D.E. (1982) Gonadotropin regimen for inducing ovarian activity in captive wild felids. J. Am. vet. med. Assoc. 181, 1246-1250.

Pursel, V.G., Wall, R.J., Rexroad, C.E., Jr, Hammer, R.E. \& Brinster, R.L. (1985) A rapid whole-mount staining procedure for nuclei of mammalian embryos. Theriogenology 24, 687-691.

Roelke, M.E. (1988) Florida Panther Recovery Florida Panther Biomedical Investigation, E-1-12, pp. 31-33. Fl. Game Fresh Wat. Fish Comm.

Saacke, R.G., Bame, J.H., Karabinus, D.S., Mullins, K.J. \& Whitman, S. (1988) Transport of abnormal spermatozoa in the artificially inseminated cow based upon accessory spermatozoa in the zona pellucida. Proc. 11th Int. Cong. Reprod. A.I., Dublin 3, 292, abstr.

Shivaji, S. \& Bhagava, P.M. (1987) Antifertility factors of mammalian seminal fluid. Bioessays 7, 13-17.

Singleton, W.L. \& Shelby, D.R. (1972) Variation among boars in semen characteristics and fertility. J. Anim. Sci. 34, 762-766.

Thomas, T.S., Wilson, W.L. \& Oliphant, G. (1986) Chemical and physical characterization of rabbit sperm acrosome stabilizing factor. Biol. Reprod. 35, 691-703.

Toyoda, Y. \& Chang, M.C. (1974) Fertilization of rat eggs in vitro by epididymal spermatozoa and the development of eggs following transfer. J. Reprod. Fert. 36, 9-22.
Wildt, D.E., Kinney, G.M. \& Seager, S.W.J. (1978) Gonadotropin-induced reproductive cyclicity in the domestic cat. Lab. Anim. Sci. 28, 301-307.

Wildt, D.E., Platz, C.C., Seager, S.W.J. \& Bush, M. (1981) Induction of ovarian activity in the cheetah (Acinonyx jubatus). Biol. Reprod. 24, 217-222.

Wildt, D.E., Bush, M., Howard, J.G., O'Brien, S.J., Meltzer, D., van Dyk, A., Ebedes, H. \& Brand, D.J. (1983) Unique seminal quality in the south African cheetah and a comparative evaluation in the domestic cat. Biol. Reprod. 29, 949-947.

Wildt, D.E., Howard, J.G., Hall, L.L. \& Bush, M. (1986a) The reproductive physiology of the clouded leopard: I. Electroejaculates contain high proportions of pleiomorphic spermatozoa throughout the year. Biol. Reprod. 34, 937-947.

Wildt, D.E., Schiewe, M.C., Schmidt, P.M., Goodrowe, K.L., Howard, J.G., Phillips, L.G., O'Brien, S.J. \& Bush, M. (1986b) Developing animal model systems for embryo technologies in rare and endangered wildlife. Theriogenology 25, 33-51.

Wildt, D.E., Bush, M., Goodrowe, K.L., Packer, C., Pusey, A.E., Brown, J.L., Joslin, P. \& O'Brien, S.J. (1987a) Reproductive and genetic consequences of founding isolated lion populations. Nature, Lond. 329, 328-33i.

Wildt, D.E., O'Brien, S.J., Howard, J.G., Caro, T.M., Roelke, M.E., Brown J.L. \& Bush, M. (1987b) Similarity in ejaculate-endocrine characteristics in captive versus free-ranging cheetahs of two subspecies. Biol. Reprod. 36, 35I-360.

Wildt, D.E., Phillips, L.G., Simmons, L.G., Chakraborty, P.K., Brown, J.L., Howard, J.G., Teare, A. \& Bush, M. (1988) A comparative analysis of ejaculate and hormonal characteristics of the captive male cheetah, tiger, leopard and puma. Biol. Reprod. 38, 245-255.

Yanagimachi, R. (1981) Mechanisms of fertilization in mammals. In Fertilization and Embryonic Development In Vitro, pp. 181-183. Eds L. Mastroinni, Jr \& J. D. Biggers. Plenum Press, New York.

Young, S.P. \& Goldman, E.A. (1946) The Puma: Mysterious American Cat. The American Wildlife Institute, Washington. 